Краснякова А. О., м. Київ

\title{
МЕРЕЖА ІНТЕРНЕТ ЯК КОМУНІКАТИВНИЙ ПРОСТІР НАЦІОНАЛЬНОЇ ТА ГРОМАДЯНСЬКОЇ САМОІДЕНТИФІКАЦІЇ КІБЕРПОКОЛІННЯ
}

Інформаційно-комунікаційне середовище мережі Інтернет розглядається як мультикультурне віртуальне середовище взаємодії носіїв різних мов і культур. Наголошується, що інтернет-простір є гібридним середовищем, яке утворюється за допомогою інформаційно-комунікаційних технологій (ІКТ) у результаті інтеграції елементів реального і віртуального життя. У процесі комунікативної взаємодії різних соціальних суб'єктів в інтернет-середовищі формуються ідентифікаційні характеристики користувача. Висвітлено особливості самоідентифікації кіберпокоління у віртуальному інтернет-просторі, зокрема: 1) процес самоідентифікування відбувається синхронно в реальному соціокультурному просторі і віртуальному мультикультурному інтернет-середовищі; 2) у віртуальному інтернетпросторі конструювання образу “Я” може здійснюватися як а) копіювання реальної ідентичності, зокрема національної та громадянської; б) утворення віртуального образу, відмінного від реальної ідентичності, а також як в) поєднання елементів віртуальної і реальної ідентичності в гібридній (за Дж. Сулером) моделі. Звертається увага на те, що можливість створювати різні “Я” образи у віртуальному інтернет-просторі приводить до формування мінливої, гнучкої, динамічної і нестабільної ідентичності. Підкреслюється, що процес самоідентифікації молодих громадян країни поєднується з кризою дитячої ідентичності, яка сформувалася в рамках наявної системи соціальних відносин під впливом батьків, і входженням у віртуальний світ Інтернету, де пропонується нові системи цінностей, норм і правил поведінки. Наведено результати дослідження особливостей самоідентифікування студентської молоді у віртуальному інтернетсередовищі. Встановлено, що переважна частина молоді (62\%) презентує в інтернет-середовищі свою реальну національну та громадянську ідентичність, третина - демонструє елементи гібридної моделі ідентичності. Зауважено, що частка молоді, яка створює тільки віртуальний образ “Я” в Інтернеті, не перевищує 1,5\%. 3'ясовано, що майже 93\% респондентів для презентації національної та громадянської ідентичності обирають візуальні форми: використовують символи, кольори, атрибути, фрагменти національного орнаменту тощо. Виявлено, що найбільш прийнятними формами інтернет-комунікації, де виявляється національна та громадянська ідентичність, молоді громадяни країни вважають інтерактивні полілоги, зокрема чати, форуми, коментарі на сторінках соціальних інтернет-мереж, обговорення в блогах та мікроблогах.

Ключові слова: інтернет-середовище, інтернет-технології, самоідентифікація, віртуальна ідентичність, гібридна модель ідентичності. 
Постановка проблеми. 3 появою всесвітньої мережі Інтернет географічна територіальність (регіональність) перестає бути головним організаційним принципом соціального і культурного життя. Завдяки вільному переміщенню інформаційних потоків, ідей, послуг користувачі здобувають доступ до загальноцивілізаційних цінностей, що сприяє формуванню багатогранного світогляду, прискорює процеси глобалізації та взаємопроникнення культур. Гомогенізація світу, плюралізація цінностей, встановлення єдиних правил оцінки тенденцій розвитку різних народів зумовлюють формування нового, трансформативного, типу ідентичності, основними характеристиками якого є множинність, варіативність, гнучкість і динамічність. У віртуальному світовому просторі формується новий тип ідентичності - “громадянин світу" - як носій глобальної культури.

Водночас глобалізація та інтернетизація поглиблюють суперечності на національному рівні, загострюють міжнаціональні конфлікти у світі. Як захисна реакція на культурне й ментальне нівелювання в багатьох країнах світу, зокрема і в Україні, розгортаються процеси національного відродження: зростає інтерес до традиційної національної культури, мови, історії, звичаїв; формується почуття любові та поваги до своєї Батьківщини, посилюється роль національної і регіональної ідентичності. Національна і громадянська ідентичність сприяє об'єднанню спільноти, розумінню національних інтересів, прагнень, цілей, ідеалів, потреб.

Не останню роль у цих процесах відіграє транскультурна і транснаціональна всесвітня мережа Інтернет. Поява національних сегментів, присвоєння їм доменних імен, зокрема й українському сегментові Інтернету доменного імені UA (19 грудня 1990 р.), створює особливі соціальнопсихологічні умови для становлення і розгортання національної та громадянської ідентичності молодих громадян країни.

Аналіз останніх досліджень і публікацій, виділення не розв'язаних раніше частин загальної проблеми. Вітчизняні та зарубіжні психологи характеризують сучасний Інтернет як новий соціальний простір існування людини, фактор народження іiі ідентичності (Асмолов, 2014), віртуальне комунікативне середовище соціалізації (Лучинкіна, 2014), самоідентифікації (Половинчак, 2017), деідентифікації особистості (Павлов, 2013); феномен творення "віртуальних особистостей” (Труфанова, 2010); новий ресурс впливу на людину (Щербина, 2002). На думку В. Щербини, інформаційно-комунікаційні технології (ІКТ), зокрема інтернет-технології (IT), дають змогу непомітно вводити в пам'ять користувачів будь-яку інформацію, формувати їхні потреби, інтереси, цінності, світогляд. Відбувається не лише мовна й культурна експансія, а й програмування певних структур свідомості та підсвідомості сучасної людини" 
(Щербина, 2002, с. 114). Як новий комунікативний простір взаємодії соціальних суб'єктів, Інтернет формує ідентифікаційні характеристики людини. Вважають, що інтернет-технології не тільки дають можливість долати географічну дистанцію, вікові, расові, гендерні перепони, знімають обмеження часових поясів, а й сприяють консолідації громадян у суспільстві, взаєморозумінню, готовності прийняти погляди іншого, виробленню спільних цінностей (Рейнгардт, 2006).

Плюралізація цінностей, уведення фрагментів різних культур, патернів поведінки в культуру і життедіяльність кіберпокоління, з одного боку, корелюють з незалежністю і свободою від тиску, жорсткої регламентації всілякого роду традицій та авторитетів, з другого - “нагромадження" нових смислів, боротьба систем цінностей в інтернет-середовищі призводять до формування готовності молоді здійснювати перехід від однієї системи цінностей до іншої. Така мінливість, нестабільність розмиває та знецінює узвичаєні (батьківські) моделі ідентичності, ускладнює становлення ідентичності молодих громадян країни, зокрема національної та громадянської, що створює певні загрози як індивідові, так і суспільству. Інформаційно-комунікаційне середовище мережі Інтернет, як транснаціональне і транскультурне, посилає кіберпоколінню виклик: як, на якому фундаменті, з яких елементів будувати свою ідентичність?

Мета статті: з'ясувати особливості самоідентифікації кіберпокоління у віртуальному інтернет-середовищі, визначити найбільш популярні серед студентської молоді форми презентації національної та громадянської ідентичності в мережі Інтернет

Виклад основного матеріалу дослідження. У контексті нашого дослідження ми спираємося на ідеї вітчизняних і зарубіжних психологів (Doering, 2003; Половинчак, 2017; Рейнгардт, 2006; Suler, 2000; Turkle, 1995; Труфанова, 2010), які стверджують, що людина ХХІ століття не належить повністю ні до реального, ні до віртуального світу, і розглядають Інтернет як гібридне середовище - “interreality”, що утворюється в результаті інтеграції елементів реального і віртуального життя за допомогою технічних засобів (Suler, 2000). Також ми враховуємо те, що в гібридному інтернет-середовищі, по-перше, індивід має безпрецедентну можливість експериментувати 3 власною ідентичністю, конструювати різні віртуальні Я-образи, а саме: в інтернет-просторі легко позбутися реальної соціальної ідентичності, змінити вік, соціальний статус, прізвище, зовнішність, мову спілкування, віросповідання, національність, громадянство, етнічну належність і навіть стать. Саме під час таких переконструювань образу “Я” у віртуальному просторі з'являються нові ідентичності, змінюються їхні взаємозв'язки, роль і валентність в ідентифікаційній структурі індивіда. Структура “Я” стає настільки складною і динамічною, 
якою не була ніколи раніше. І чим більше Я-образів створює особа, зауважує Труфанова (2010), тим складніше зберігати їхню зв'язність і послідовність (с. 105). По-друге, в інформаційному суспільстві, на відміну від суспільства індустріального, "рамки” ідентифікації (термін Маркузе, 1994 , с. 14-15) стають більш прозорими і дозволяють уникати “скам'яніння” традиційних моделей ідентичності. Ототожнюючи себе 3 певною соціальною групою, спільнотою (етнічною, національною), молода людина синхронно опановує мозаїчний, мультикультурний інтернетпростір, у якому комунікує з носіями різних мов і культур. Адаптуючись кожного разу до нової інформації, нове покоління громадян стає більш прагматичним, легко змінює “маски”, переконання, намагається у віртуальному середовищі уникати фіксації ідентичності. По-третє, "ризомний” (ризома не має чітко вираженого центрального кореневища) характер віртуального комунікативного інтернет-простору, можливість автономно здійснювати свій вибір в інтернет-середовищі, ігнорування соціальних статусів спричинюють динамічність і варіативність ідентичності. У процесі взаємодії з різними соціальними суб'єктами в інтернет-середовищі ідентичність людини може втрачати одні елементи і набувати інших.

За оцінками вчених, розрив із традиціями і здобутками минулого, відмова від історичного досвіду руйнують ідентифікаційні механізми людини, спричинюють втрату ії залежності від “землі і крові”, породжують відчуття “бездомності”, “безбатьківщини”, запускають процес деідентифікації і провокують кризу ідентичності (Павлов, 2013; Половинчак, 20017; Труфанова, 2006). На погляд Ю. Павлова, деідентифікація і криза ідентичності пов'язані з інформаційним перевантаженням сучасної людини. Користувачі Інтернету, на його переконання, живуть виключно проблемами сьогодення і не замислюються над тим, що було в минулому, яке їх чекає майбутнє. Мережа Інтернет ніби вилучає кіберпокоління із системи "минуле - сьогодення - майбутнє", знімає з індивіда відповідальність за результати діяльності як щодо сучасників, так і щодо майбутніх поколінь. Як наслідок, з'являються комплекси егоцентризму, морального релятивізму (Павлов, 2013).

У значної частини молоді на процес національної та громадянської самоідентифікації накладається криза дитячої ідентичності - ідентичності, що сформувалася в межах чинної системи соціальних відносин під впливом батьків та входження у віртуальний світ Інтернету, де замість однієї, традиційної, “батьківської”, системи цінностей пропонується чимало нових систем цінностей, норм і правил поведінки, які конкурують між собою. Молодій людині, яка не має достатнього життєвого досвіду, усталених орієнтирів і моральних зразків поведінки, важко віднайти власне “Я”. Долучення індивіда до віртуального інтернет-середовища завжди 
потребує створення віртуального Я-образу, яке може відбуватися: а) як копіювання (віддзеркалення) реальної ідентичності людини, у т. ч. національної і громадянської; б) як створення віртуального (від virtualis - вигаданий, уявний, можливий) образу, відмінного від реального суб'єкта або навіть альтернативного йому; а також в) як поєднання елементів реальної та віртуальної ідентичності в "гібридному образі".

Наразі відомо чимало наукових досліджень мотивів створення індивідом віртуального образу, відмінного від реального “Я” (Doering, 2003; Костерина, 2008; Половинчак, 2017; Suler, 2000; Труфанова, 2010). Утім, серед учених все більшої популярності набуває ідея про те, що користувачі мережі конструюють не саму ідентичність, а свого роду “віртуальну оболонку" для неї. Завдяки розвитку інтерактивних інтернет-технологій третього покоління Web-3 (соціальні мережі, блоги, чати, форуми тощо) суб'єкти мають змогу зберігати свою індивідуальність. І. Костеріна (2008), спираючись на результати дослідження особливостей ідентифікації блогерів, робить висновок: "Гра з віртуальною ідентичністю стає все більше непопулярною. Користувачі Інтернету не хочуть бути "безликими" та носити іншу соціальну маску - навпаки, вони прагнуть створити в Мережі такий індивідуальний профіль онлайнового “Я”, який би відрізнявся від усіх інших (Костерина, 2008, с. 187). На думку Н. Дьорінга, прагнення індивіда відрізнятися від інших формує певні риси "постійного користувача", за якими його впізнають інші суб'єкти взаємодії. Так утворюється “онлайнова ідентичність актора” у віртуальному просторі (Doering, 2003).

Слушними в контексті нашого дослідження видаються:

- положення теорії О. Горошко, зокрема про те, що ідентичність формується в результаті багатьох комунікативних процесів, основними серед яких є інтеракція, ідентифікація та інтеріоризація; витоки віртуальної комунікативної ідентичності слід шукати в організації інтернетспільнот, які є середовищем соціального життя молодої людини, іiї комунікативної взаємодії з іншими (Горошко, 2009, с. 184);

- кониепиія Дж. Сулера щзодо самоконструювання образу “Я” за допомогою вербальних і невербальних засобів інтернет-комунікації, що $\epsilon$ результатом самоідентифікаиії особистості в інтернет-середовищі (Suler, 2000);

- ідея конкретного моменту ідентифікації Т. Омонії. За Омонії, образ, який автономно створює суб'єкт, аби пред'явити інформацію про себе іншим користувачам Інтернету, є відображенням його ідентичності лише в конкретний момент ідентифікації (Omoniyi, 2006).

Отже, можемо виокремити такі особливості самоідентифікації кіберпокоління: 1) самоідентифікування індивіда відбувається синхронно в реальному соціальному просторі і мультикультурному віртуальному ін- 
тернет-середовищі. У гібридному (змішаному, синтетичному) інтернетсередовищі індивід має змогу конструювати і презентувати новоутворений образ “Я”; 2) у віртуальному інтернет-просторі самоконструювання образу “Я”може здійснюватися як копіювання реальної ідентичності, зокрема національної та громадянської; утворення віртуального образу, відмінного від реальної ідентичності, а також поєднання елементів віртуальної і реальної ідентичності в гібридній (за Дж. Сулером) моделі (рис.).

Щоб визначити особливості самоідентифікації української молоді, ми розробили анкету “Я в Інтернеті" (Краснякова, 2016) і протягом 2018 р. опитали 158 студентів останніх курсів столичних закладів вищої освіти віком від 18 до 27 років. Результати опитування показали, що переважна більшість респондентів (62\%) презентують себе у віртуальному інтернет-середовищі як реальну людину, громадянина/рромадянку Украї$н и$; використовують шаблонний інтерфейс, розміщують власні фото на сторінках соціальних інтернет-мереж. Кожний третій респондент зазначив, що застосовує створений у віртуальному просторі “нік” або “аватар" як під час спілкування 3 друзями в соціальних інтернет-мережах, так і в реальному житті; у віртуальному просторі інколи відчуває себе “людиною світу, разом з іншими користувачами мережі Інтернет”, при цьому “ніколи не забуває, що є громадянином України”.

Про “свій досвід створення віртуального образу, відмінного від реального", повідомили тільки 10 осіб (1,5\%); при цьому респонденти не зазначали мотиви створення віртуального образу “Я”. Найбільш популярними формами самопрезентації національної та громадянської ідентичності респонденти визнали створення акаунта/акаунтів (від англ. account обліковий запис як сукупність реальної інформації) в автономно обраних соціальних інтернет-мережах. Студенти зазначали, що для презентації національної та громадянської ідентичності частіше обирають і застосовують візуальні (а не текстові) форми, зокрема використовують символи, кольори, атрибути, фрагменти національного орнаменту, власні фото, якот світлини “зі свята вишиванки” тощо. Випробувані вважають, що “візуальні форми точніше відображають національний характер користувача" i “дають змогу швидко ідентифікувати особу”.

Що ж до найбільш бажаних форм і способів представлення власної громадянської позиції, то переважна більшість респондентів (майже 93\%) уникають спілкування у своїх онлайнових групах на теми національної та громадянської ідентичності, а найбільш прийнятними формами презентації громадянської позиції вважають інтерактивні полілоги, зокрема чати, форуми, коментарі на сторінках соціальних інтернет-мереж, обговорення в блогах і мікроблогах. 


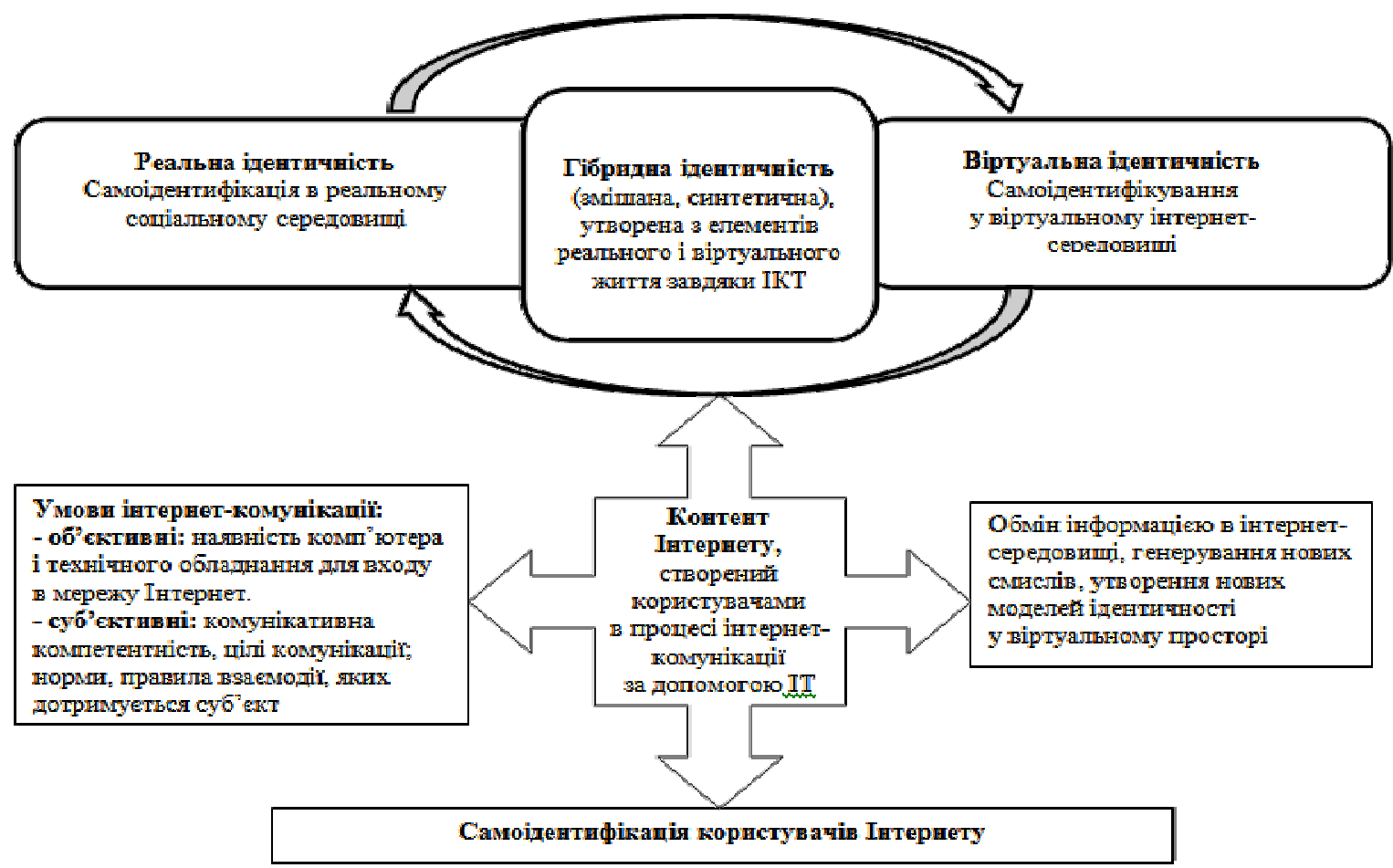

Рис. Особливості самоідентифікації користувачів Інтернету 


\section{Висновки:}

1. Становлення національної та громадянської ідентичності молодих громадян країни відбувається синхронно в соціокультурному просторі і мультикультурному віртуальному інтернет-середовищі. У процесі комунікації в інтернет-просторі користувачі взаємодіють 3 реальними соціальними суб' єктами, а також створеними віртуальними образами. У результаті інтеграції елементів реального і віртуального життя утворюється гібридне середовище, яке сприймається як цілком реальне.

2. У гібридному (змішаному, синтетичному) інтернет-середовищі особа має змогу автономно конструювати образ/образи “Я” і презентувати його/іх у віртуальному просторі Інтернету. Самоконструювання може відображати: а) реальну національну та громадянську ідентичність; б) новоутворену “віртуальну ідентичність", відмінну від реальної громадянської та національної ідентичностей, або в) гібридну (за Дж. Сулером), змішану ідентичність, що виникає в результаті перетину елементів реального та віртуального життя суб'єкта в конкретний момент ідентифікації.

3. Результати емпіричного дослідження показали, що переважна частина респондентів позиціонує в інтернет-середовищі свою реальну національну та громадянську ідентичність, третина демонструє елементи гібридної моделі ідентичності. Частка молоді, яка створює в Інтернеті віртуальний образ “Я”, відмінний від реального, не перевищує 1,5\%. Найбільш популярними формами прояву громадянської та національної ідентичності студентська молодь вважає інтерактивні форми комунікативної взаємодії в інтернет-середовищі, зокрема блоги, чати, полілоги в соціальних інтернет-мережах.

Перспективи дослідження. У подальших наукових дослідженнях предметом розгляду може бути інтернет-середовище як ресурс розвитку громадянської компетентності студентської молоді.

\section{Список використаних джерел}

Асмолов, А. Г. (2014). Идентичность реальная и виртуальная. Взято из http://vogazeta.ru/ivo/info/14423.html

Горошко, Е. И. (2009). Коммуникативная виртуальная идентичность: гендерный анализ. Филологические заметки. Пермский государственный университет. Пермь - Скопье - Любляна - Загреб. Вып. 7. Ч. 2, с. 93-105.

Костерина, И. В. (2008). Публичность приватных дневников: Об идентичности в блогах Рунета. Неприкосновенный запас: Дебаты о политике и культуре, 3, 183-191.

Краснякова, А. О. (2016). Інтернет-середовище як новий комунікативний простір самопрезентацій особистості. Наукові студії із соціальної та політичної психології, 38 (41), 286-297. 
Лучинкіна, А. І. (2014). Психологічні закономірності соціалізації особистості у віртуальному просторі. (Автореф. дис. д-ра психол. наук). Інститут психології ім. Г. С. Костюка, Київ.

Маркузе, Г. (1994). Одномерный человек. Москва: REFL-book.

Павлов, Ю. В., (2013). Постмодерністські версії “деідентифікації” сучасної людини. Наукові записки. Серія “Культурологія". Матеріали VI Міжнародної наукової конференції "Культура в горизонті сталих і плинних ідентичностей" (12-13 квітня 2013 року, $\quad$ м. Острог), Ч. 2, с. 314-318. Взято 3 https://eprints.oa.edu.ua/1875/

Половинчак, Ю. М. (2017). Сучасне інформаційно-комунікаційне середовище як простір трансформації української національної ідентичності. Взято 3 ttp://nbuviap.gov.ua/images/nauk-mon/suchasne\%20informatsiino-komunikatsiine\%20 seredovyshche.pdf

Рейнгардт, Н. В. (2006). Трансформация идентичности человека в информационно-компьютерном мире. Взято из http://www.dissercat.com/content/ transformatsiya-identichnosti-cheloveka-v-informatsionno-kompyuternommire\#ixzz4QBXmHgL3

Труфанова, Е. О. (2010). Роль коммуникации в построении личностной идентичности. Вопросы философии, 15, 128-142. Взято из https://cyberleninka.ru/article/n/rol-kommunikatsii-v-postroenii-lichnostnoyidentichnosti

Щербина, В. М. (2002). Сітьова кіберкомунікація як соціальний феномен. Соиіологія: теорія, методи, маркетинг, 1, 109-116.

Doering, N. (2003). Sozialpsychologie des Internet. Hogrefe Verlag.

Omoniyi, T. (2006). Hierarchy of Identities. In Omoniyi, T. and White, G. (Eds.), The Sociolinguistics of Identiy (pp. 11-33). London: Continuum.

Suler, J. (2000). Identity Management in Cyberspace. Retrieved from http://users.rider.edu/ suler/psycyber/identitymanage.

Turkle, S. (1995). What Are We Thinking about When, We Are Thinking about Computers? Retrieved from http://web.mit.edu/sturkle/www/routledge_reader.

\section{References}

Asmolov, A. G. (2014). Identichnost realnaya i virtualnaya [Identity is real and virtual]. Retrieved from http://vogazeta.ru/ivo/info/14423.html. (in Russian)

Goroshko, Ye. I. (2009). Kommunikativnaya virtualnaya identichnost: gendernyy analiz [Communicative virtual identity: gender analysis]. Filologicheskiye zametki. Permskiy gosudarstvennyy universitet [Philological Notes. Perm State University]. Is. 7. Part 2, pp. 93-105. Perm - Skopye - Lyublyana - Zagreb. (in Russian)

Kosterina, I. V. (2008). Publichnost privatnykh dnevnikov: Ob identichnosti v blogakh Runeta [Publicity of private diaries: Identity on Runet blogs]. Neprikosnovennyy zapas: Debaty o politike $i$ kulture [Immaculate Reserve: Debates on Politics and Culture], 3, 183-191. (in Russian)

Krasnyakova, A. O. (2016). Internet-seredovyshche yak novyi komunikatyvnyi prostir samoprezentatsiy osobystosti [Internet environment as a new communicative space for personal self-representations]. Naukovi studii iz sotsialnoi ta politychnoi psykholohii, 38 (41), 286-297. (in Ukrainian) 
Luchynkina, A. I. (2014). Psykholohichni zakonomirnosti sotsializatsii osobystosti u virtualnomu prostori [Psychological patterns of personality socialization in virtual space]. Kyiv. (in Ukrainian)

Marcuse, H. (1994). Odnomernyy chelovek [One-dimensional man]. Moscow: REFL-book. (in Russian)

Pavlov, Yu. V. (2013). Postmodernistski versii “deidentifikatsii” suchasnoi lyudyny [Postmodern versions of "Detection" of modern man]. Naukovi zapysky. Seriia "Kulturolohiia”. Materialy VI Mizhnarodnoi naukovoi konferentsii "Kultura v horyzonti stalykh i plynnykh identychnostei" [Scientific Notes. Series "Culturology". Materials of the VI International Scientific Conference "Culture in the Horizon of Sustainable and Flowing Identities” (April 12-13, 2013, Ostroh]. Ch. 2, pp. 314-318. Retrieved from https://eprints.oa.edu.ua/1875/ (in Ukrainian)

Polovynchak, Yu. M. (2017). Suchasne informatsiino-komunikatsiine seredovyshche yak prostir transformatsii ukrainskoi natsionalnoi identychnosti [Modern Information and Communication Environment as a Space for the Transformation of Ukrainian National Identity]. Retrieved from http://www.dissercat.com/content/ transformatsiya-identichnosti-cheloveka-v-informatsionno-kompyuternommire\#ixzz4QBXmHgL3 (in Ukrainian)

Reingardt, N. V. (2006). Transformatsiya identichnosti cheloveka $v$ informatsionno-kompyuternom mire [Transformation of Human Identity in the InformationComputer World]. Retrieved from http://www.dissercat.com/content/ transformatsiyaidentichnosti-cheloveka-v-informatsionno-kompyuternom-mire\#ixzz4QBXmHgL3 (in Russian)

Trufanova, Ye. O. (2010). Rol kommunikatsii v postroyenii lichnostnoy identichnosti [The role of communication in the construction of personal identity]. Voprosy psikhologii, 15, 128-142 (in Russian)

Scherbyna, V. (2002). Sitova kiberkomunikatsiia yak sotsialnyi fenomen [Networked kiberkomunikatsiya as a social phenomenon], Sotsiolohiia: teoriia, metody, marketynh [Sociology: theory, methods, marketing], 1, 109-116. (in Ukrainian)

Doering, N. (2003). Sozialpsychologie des Internet. Hogrefe Verlag.

Omoniyi, T. (2006). Hierarchy of Identities. In Omoniyi, T. and White, G. (Eds.), The Sociolinguistics of Identiy (pp. 11-33). London: Continuum.

Suler, J. (2000). Identity Management in Cyberspace, Retrieved from http://users.rider.edu/ suler/psycyber/identitymanage.

Turkle, S. (1995). What Are We Thinking about When, We Are Thinking about Computers? Retrieved from http://web.mit.edu/sturkle/www/routledge_reader.

\section{Alla O. Krasniakova. The Internet environment as communication space of national and civic self-identification of the cyber generation}

The author investigates the Internet information and communication environment as amulticultural virtual space of interaction of people speaking different languages and representing different cultures. The Internet space is a hybrid environment created by means of the information and communication technologies (ICT) in the course of integration of the elements of real and virtual life. In the process of interaction between different social subjects user's identification features are developed in the Internet environment. The author considers the following peculiarities of selfidentification of the cyber generation in the Internet space. Self-identification process 
proceeds simultaneously in the real socio-cultural space and in the virtual Internet environment. The self image construction in the virtual Internet space occurs by a) copying of the real identity, particularly national and civic identity; b) creation of the virtual image, which is different from the real identity; c) combination of the elements of the virtual and real identities in the hybrid model (according to J. Suler). The possibility to create different self images in the virtual Internet space causes the development of the changeable, dynamic and unstable identity. The author argues that the process of selfidentification of the young citizens of the country is combined with the crisis of their child identity formed in the framework of the actual system of social relations under the influence of the parents and their involvement in the virtual world of the Internet with its new systems of values, norms and rules of behavior. An empirical study of the peculiarities of the student self-identification in the virtual Internet environment proves that the majority of the young people $(62 \%)$ present their real national and civic identity in the Internet environment, and one third of the students demonstrate elements of the hybrid identity model. The portion of young people who create only a virtual self image do not exceed $1.5 \%$. Almost $93 \%$ of the respondents choose visual forms of presenting their national and civic identity. They use symbols, colors, attributes, fragments of the national patterns and other forms. The most acceptable forms of the Internet communication in which national and civic identities manifest themselves are interactive polylogues, namely charts, forums, commentaries on social network sites, blogs and micro blogs.

Key words: Internet environment, Internet technologies, self-identification, virtual identity, hybrid identity model. 